Yury G. Chendev ${ }^{1 *}$, Aleksandr N. Petin ${ }^{1}$, Anthony R. Lupo ${ }^{2}$

${ }^{1}$ Russia, National Research Belgorod State University; 308015, Belgorod, Pobeda St. 85;

* Corresponding author e-mail: Chendev@bsu.edu.ru

2 USA; University of Missouri; 302 Anheuser-Busch Natural Resources Building,

Columbia, MO 65211-7250; e-mail: LupoA@missouri.edu

\title{
SOILS AS INDICATORS OF CLIMATIC CHANGES
}

ABSTRACT. A number of examples for the reaction of chernozems in the center of the East European Plain and their relation to different periodical climatic changes are examined. According to unequal-age chernozems properties, the transition from the Middle Holocene arid conditions to the Late Holocene wet conditions occurred at $4000 \mathrm{yr}$ BP. Using data on changes of soil properties, the position of boundary between steppe and forest-steppe and the annual amount of precipitation at approximately $4000 \mathrm{yr}$ BP were reconstructed. The change from warm-dry to cool-moist climatic phases, which occurred at the end of the XX century as a reflection of intraage-long climatic cyclic recurrence, led to the strengthening of dehumification over the profile of automorphic chernozems and to the reduction of its content in the upper meter of the soils. The leaching of carbonates and of readily soluble salts contributed to the decrease in soil areas occupied by typical and solonetzic chernozems, and to the increase in areas occupied by leached chernozems.

KEY WORDS: chernozems, climate change, Holocene, forest-steppe, steppe.

\section{INTRODUCTION}

Among the diverse objects in the natural environment, the soils are rightfully considered one of the most informative components. They contain the records not only of contemporary, butalso of past physicalgeographical and climatic conditions. At the same time, the soil is a rapidly changing system, which sensitively reacts to changes in natural conditions and, in the first place, to climate change. Therefore, in scientific literature in connection with soils, arose such concepts as "soil-moment" and "soilmemory", "urgent" and "relict" characteristics of soils, and "sensitivity" and "reflectivity" of soil properties [Aleksandrovskii, 1983; Gennadiev, 1990; Sokolov and Targul'yan, 1976; Sokolov, et al., 1986; and others].

In contemporary world geography, there still remains a paucity of information on the many-sided interrelations of soils with the other components of the natural environment. This is extremely important aspect in light of current global ecological problems, studies, and policy decisions, one of which is the problem of climate change.

While these have been long discussed by scientists, this problem during the last few years acquired new urgency in connection with new data, reflecting "long" sequences in paleoclimatic reconstructions and a comparatively short, but detailed series of instrumental observations [Climate..., 2002; Climate..., 2008; Global..., 2000; and others]. We will continue the discussion on the following questions: "In what direction might the change in global climate go?" and "Is this change subordinated by trend dependence or does it occur within cyclic climatic dynamics?" [Bunyard, 2001; Lupo, 2008; and others]. It seems that in finding new ways and approaches to this problem it may be possible to find a solution to a number of other problems and the solution 
must be connected with a thorough study of soils as indicators of climate change.

The role of soils in the study of chronological variations of climate is reflected in a number of publications, many of which are oriented toward the use of soils in reconstructions of long-term climate changes [Aleksandrovskii and Aleksandrovskaya, 2005; Buol et al., 1997; Chendev, 2008; Climate..., 2009; FelixHenningsen, 2000; Gennadiev, 1990; Ivanov, 1992; Jenny, 1941; and others]. There are fewer references on the study of soils as indicators of contemporary climate change [Ovechkin and Isaev, 1985; Savin, 1990; Solovyov, 1989; and some others].

The main purpose of this paper is identification of forest-steppe and steppe chernozems reactions to climate change with different periodicities.

The stated purpose assumed solution of the following objectives:

- using a number of examples, to show the effectiveness of unequal-age chernozems properties in paleoclimatic reconstructions;

- to discuss the influence of short-term climate changes on properties and areas of chernozems dynamics.

\section{DISCUSSION OF THE PROBLEM, OBJECTIVES, AND METHODS}

Contemporary soil cover within the territory of East European forest-steppe and steppe began to form in the Early Holocene - approximately 10000 years ago [Aleksandrovskii, 1983; Gennadiev, 1990; Ivanov, 1992]. In the study region, climate repeatedly changed during the Holocene, which led to the time-spatial changes of the boundaries for natural and soil zones. The natural-climatic periodization of the Holocene for East Europe according to BlyttSernander [Aleksandrovskii, 1983; Ivanov, 1992] is widely known. However recently, the appropriateness for wide interpretation of this scheme, originally created for Scandinavia, is open for discussion [Aleksandrovskii and Aleksandrovskaya, 2005; Aleksandrovskii and Chendev, 2009]. In our understanding, from the point of view of age-long (longperiodical) climate change in the territory of the forest-steppe and steppe zones of the central part of the East European Plain, it is better to use division of the Holocene into Early, Middle, and Late period. According to contemporary ideas, the Early Holocene (10000-8000 yr BP) was characterized by a cool-cold and dry climate. The Middle Holocene (8000-4000 (3500) yr BP) had alternation of temperature drops and rises in conditions of dry, in general, climate; and the Late Holocene (last 4000-3500 yr) was characterized by a reduction in the degree of continentality and an increase of the climate humidity [Aleksandrovskii and Aleksandrovskaya, 2005; Aleksandrovskii and Chendev, 2009; Chendev, 2008]. In respect to evolution of chernozems in the Holocene in the East European Plain, there remain a number of only weakly illuminated questions. Among these questions: the determination of the exact chronological boundary between the Middle and the Late Holocene and identification of the distance of the shift of climatic border between forest-steppe and steppe that occurred at the beginning of the Late Holocene. The answers to these questions are discussed in this paper.

The well-known ideas of the Holocene natural periodization consider only longterm fluctuations in climate, whose tracks can be revealed in soil profiles. However, for secular variations in the climate background, there were short-term variations whose influence on soils and soil cover is studied rarely at present. L.V. Klimenko [1992] analyzed seasonal behavior of temperatures, using the data provided by a meteorological network, located in the southern half of the East European Plain $\left(45^{\circ}-55^{\circ} \mathrm{N} 30^{\circ}-50^{\circ} \mathrm{E}\right)$ for 1891-1990. In the researcher's opinion, the natural fluctuations of the temperature in both the summer and winter seasons for the past 100 years show the presence of two large waves of temperature decrease 
during the summer time (1920s-1930s and 1970s-1980s); coincident with them were temperature increases during the winter seasons. L.V. Klimenko explains these by finding that similar atmospheric processes occurring in different seasons can lead to different climatic effects. For example, since the beginning of the 1970s, cyclonic activity increased sharply, and in the cold season, positive anomalies of temperature began to appear more frequently, but, in the warm season, negative anomalies appeared. The latter result is reflected by an increase in cloudy weather with precipitation [Klimenko, 1992].

According to A.N. Sazhin and O.V. Kosina [2000], in the Northern Hemisphere during the atmosphere circulation epoch of the 1890s1920s, the annual amount of precipitation exceeded the long-term climatic norm. In the 1920s, a new atmospheric regime became established, and this continued into the middle 1950s. During this epoch, global temperatures rose, precipitation decreased, which caused more frequent droughts and these occurred repeatedly in the ordinarysteppe and dry-steppe regions of East Europe. From the beginning of the middle 1950s, in the extreme southeast of Russia's European territory, the climate steadily moistened and reached its maximum in the 1990s-2000s. With increasing precipitation, the character of many natural processes significantly changed: within the chernozem zone, the level of the ground water increased; the composition of natural vegetation changed sharply. Hygrophilous forms of plants appeared and the activity of wind-erosion processes decreased. The authors suggested that during the first half of the XXI century, changes in climate and the connected changes in the regime of temperaturemoisture potential will occur in a manner similar to the period of the 1920s-1950s. This will lead to a sharp worsening in the natural climatic conditions for the development of agriculture within the southern East European Plain [Sazhin and Kosina, 2000].

The main subjects of our study are the chernozem soils, situated in the center of the East European Plain.
For climate change, the following properties of chernozems were examined: their humus horizons thickness and depth of effervescence (depth of the upper boundary of carbonates in the soil profile). Also, we analyzed temporal change in the areas of different genetic groups of chernozems (leached, typical, solonetzic) as the reflection of climate change.

According to the existing ideas, with an increase in climatic continentality (strengthening aridization of climate), the humus horizon thickness and the depth of effervescence decrease, while the area of chernozems, characteristic for more arid climatic conditions, increase. A decrease in climate continentality (during moistening of climate) causes the opposite processes: the humus horizon thickness and the depth of effervescence grow and the area of chernozems, formed under more dry climatic conditions, decreases.

Paleoclimatic reconstructions based on data on temporal changes of soil properties were done by the method of soil chronosequences. This method can be described as the study of chernozems covered by unequal-age burial mounds, with a subsequent comparative analysis of their humus horizon thickness and depths of effervescence. Additionally, the method uses a comparison of the ancient chernozems properties together with the properties of modern (background) chernozems formed on the natural topographic surface of the adjacent mounds. The results of the examination of soils as the objects of the paleoclimatic reconstructions were compared with the conclusions of other studies based on the use of other paleoclimatic indicators. Specifically, pollen spectra of the Holocene deposits and soils were used in earlier studies and here. In this article, one of the methods of soil chronosequences applications was the identification of climatic boundary position between the steppe and the forest steppe zones $4000 \mathrm{yr} \mathrm{BP}$ and its comparison with the modern position. 
Repeated measurements (observations) and repeated cartography (comparison of maps for different years) were used to study the influence of short-term climate change (for the end of the $X X$ - the beginning of the $X X I$ centuries) on the properties and areas of chernozems. Using the Belgorod Region as an example, short-term climatically induced changes were mapped for the periods 1951-1980 and 1971-2000. These maps and literature data were the basis of our discussion on causes of relatively fast changes of soil properties and soil areas. In this discussion, we used observations and the large-scale soil surveys, which were conducted at 20-30-yr-long intervals.

\section{RESULTS AND DISCUSSION}

Using literature data and the results of our own field studies, the authors produced calculations of change in the thickness of the humus horizons (A1 + A1B) for the chernozems of the steppe zone (a subtype of ordinary chernozems) formed on flat watersheds and on loess carbonated loams, for the time-interval from $5200 \mathrm{yr}$ BP to the present (Fig. 1).

The study region is delineated by the coordinates $49^{\circ}-51^{\circ} \mathrm{N}$ and $35^{\circ}-37^{\circ} \mathrm{E}$. The graph of the soil type (Fig. 1B) was constructed and then correlated with the curve of chronological variation of the natural zones boundaries within southern forest-steppe of the river Don basin (data obtained from E.A. Spiridonova [1991]) (Fig. 1A). The data from [Spiridonova, 1991] are based on the analysis of the pollen spectra from the Holocene deposits; soils have been dated by the radio-carbon method.
As can be seen in Fig. 1, the basic extrema during the end of the Middle Holocene to the beginning of the Late Holocene, which were discovered through changes in the chernozems humus horizon thickness, are the same as on the pollen spectra variations. These were coincident with increases in the hydrothermal coefficient (during episodes of forest invasion to steppe). Then there was a decrease in their thickness observed to take place in the stages of climatic aridization (during reduction in hydrothermal coefficient values and advance of steppes to the north).

The smoothed row of the chernozems humus horizons thickness chronological variation (Fig. 1C) clearly reflects the presence of two large climatic epochs: the epoch of climate aridization, during which the humus horizons thickness was reduced, and the epoch of climate moistening, during which an increase in the humus horizons thickness occurred. The boundary between these epochs corresponds to 4000 yr BP. Specifically, this boundary should be considered as the beginning of the Late Holocene in the territory of the steppe and forest-steppe zones within the Central East European Plain. A trend toward improvement in the soil characteristics (an increase in the humus horizons thickness and the growth of the upper boundary of carbonates depth in soil profiles) as a consequence of humidity increase, was also observed for the first half of the Late Holocene within the East Europe chernozem area. This is reflected in Table 1.

In accordance with the existing ideas about the climatically induced shift of the

Table 1. Changes in the morpho-genetic properties of typical chernozems within the East European Plain forest-steppe area during the last 4000 years, \% of modern values (based on [Chendev, 2008])

\begin{tabular}{|c|c|c|c|}
\hline \multirow{2}{*}{ Soil index } & \multicolumn{3}{|c|}{ Chrono-interval } \\
\cline { 2 - 4 } & $\begin{array}{c}\mathbf{4} 000 \mathrm{yr} \mathrm{BP} \\
\boldsymbol{n} \mathbf{3}\end{array}$ & $\begin{array}{c}\text { 3500-3000 yr BP } \\
\boldsymbol{n}=\mathbf{8}\end{array}$ & $\begin{array}{c}\mathbf{2 6 0 0 - 2 2 0 0} \mathrm{yr} \mathrm{BP} \\
\boldsymbol{n}=\mathbf{1 5}\end{array}$ \\
\hline Thickness of A1+ A1B & $71.67 \pm 2.92$ & $76.50 \pm 1.93$ & $103.33 \pm 2.80$ \\
Depth of effervescence & 0 & $55.00 \pm 4.73$ & $64.73 \pm 7.18$ \\
\hline
\end{tabular}



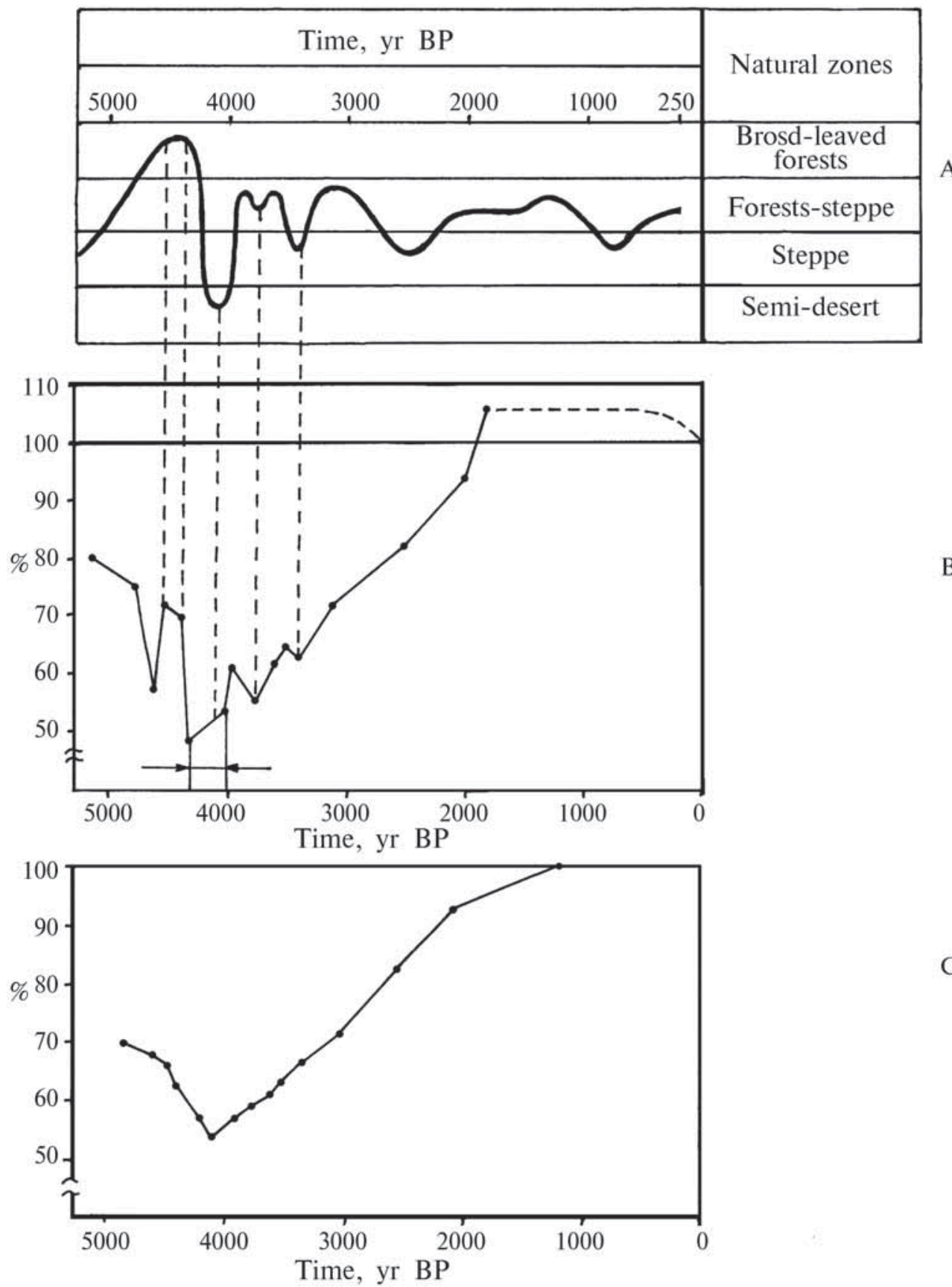

Fig. 1. Evolution of natural zones within southern forest-steppe of the river Don basin (according to [Spiridonova, 1991]) (A), and the chronological variation of chernozems humus horizons (A1 + A1B) within the steppe zone of the Central East European Plain,\% from contemporary values (B - empirical row, C - smoothed row (based on the data of [Aleksandrovskii, 1983; Aleksandrovskii and Aleksandrovskaya, 2005; Chendev, 2008; Ivanov, 1992] and the results of field studies of the authors) 


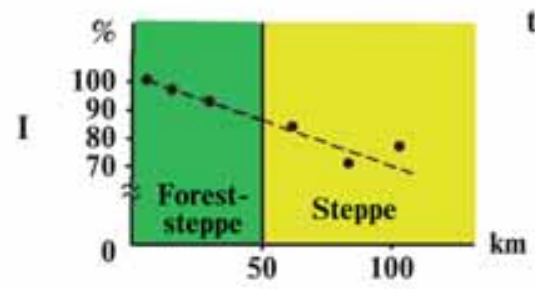

$31 \%$
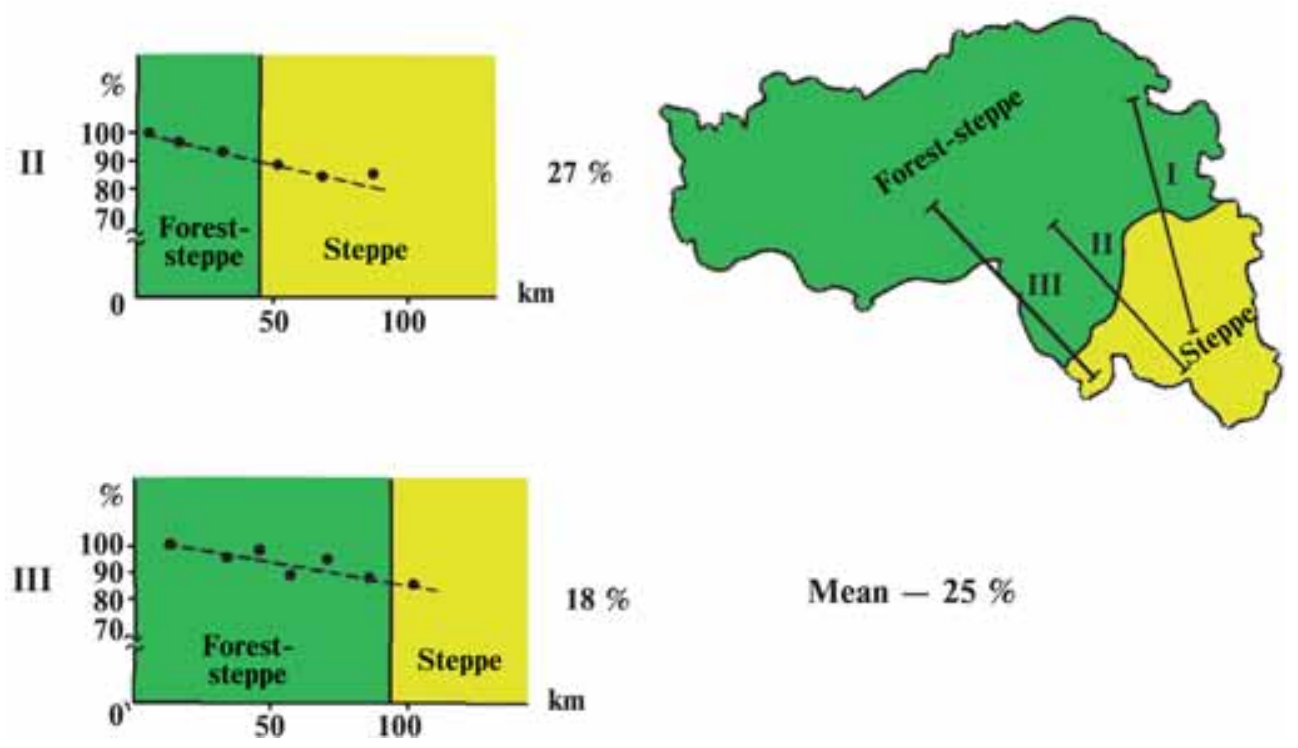

Fig. 2. Linear changes of the chernozems humus horizons (A1+A1B) thickness near the modern boundary between forest-steppe and steppe (the authors' data)

southern boundary of the forest-steppe zone at the beginning of the Late Holocene [Aleksandrovskii, 1983; Aleksandrovskii and Aleksandrovskaya, 2005; Spiridonova, 1991], we set our goal to determine where the location of the boundary between the steppe and the forest-steppe zones existed at approximately $4000 \mathrm{yr}$ BP. The method utilized here consisted of the calculation of the spatial change gradient of the humus horizons thickness for the watershed chernozems in the direction from a more humid forest-steppe to a more arid steppe chernozems (Fig. 2, transects I-III). The data from the morpho-genetic properties of contemporary chernozems were generated from the materials of the large-scale soil survey of the Belgorod region (archive information). Each point of the transects characterizes the mean arithmetic thickness of the humus profiles from 10-15 locations that are situated within a radius of $5 \mathrm{~km}$ from the point of determination. The thickness of the northernmost chernozems was accepted as 100\%.

As can be seen from Fig. 2, under contemporary conditions, the value of the thickness decreases for every $100 \mathrm{~km}$ and varies from 18 to $31 \%$ ( $25 \%$ on average). If the 4000-yr-BP's thickness of the humus profiles for paleochernozems in the southern part of the forest-steppe zone was equal to about $72 \%$ of the background (modern) values (Table 1), then, according to our calculations, the steppe zone, at this time, could be found about $112 \mathrm{~km}$ to the northwest of its contemporary position. In the southeastern direction, the annual amount of precipitation at the indicated distance decreased by $80 \mathrm{~mm}$. Consequently, near the contemporary boundary of forest-steppe and steppe, 


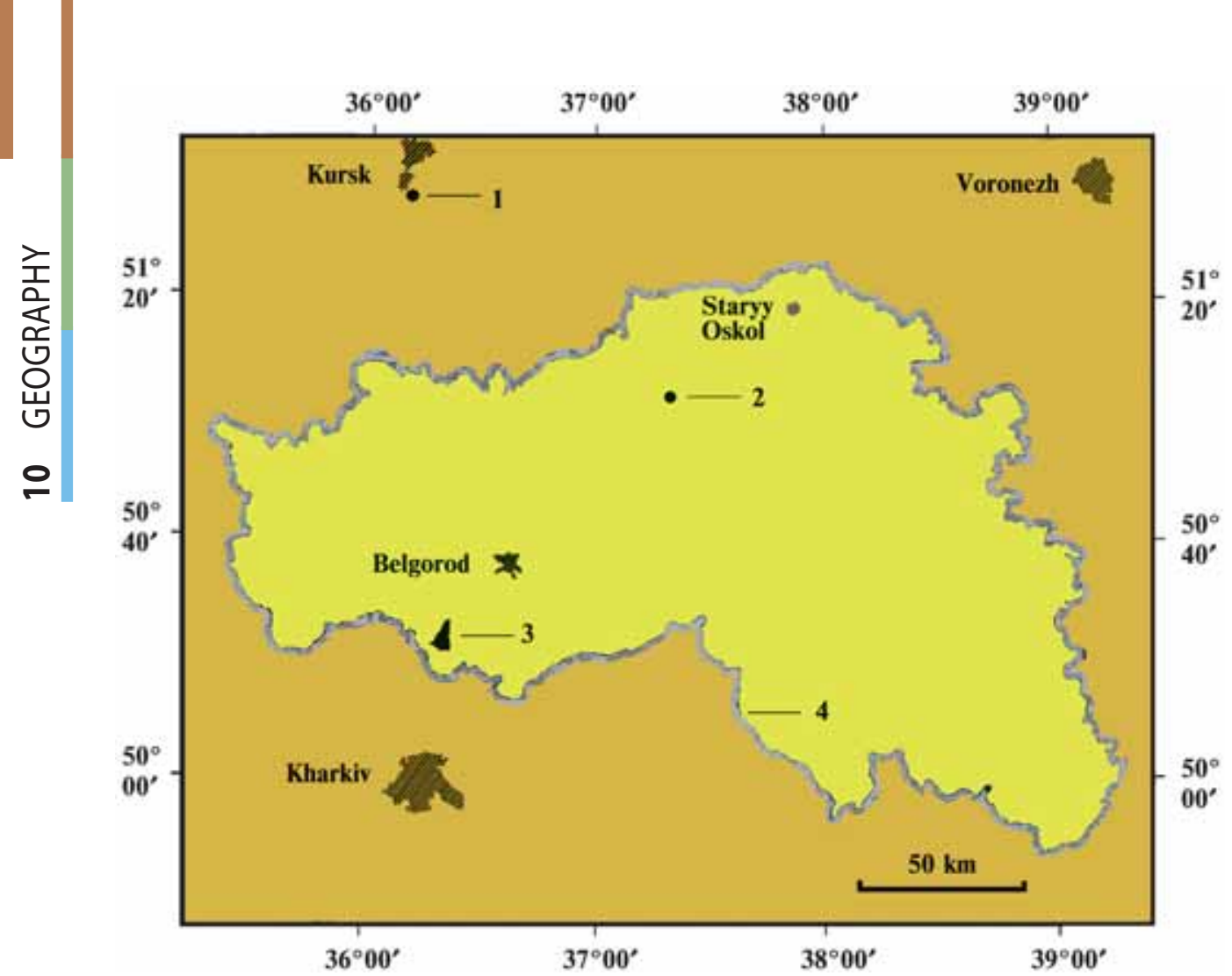

Fig. 3. The location of the study plots used to assess the short-term periodic climate change influence on soils and soil cover dynamics.

Plots: 1 - "Streletskaya Step"; 2 - "Yur'evka"; 3 - "Octyabr'skii" (plots 1 and 2 are shown not to scale); 4 - administrative border of the Belgorod Region

the climate of 4000 yr BP was more arid than contemporary (probably, $80 \mathrm{~mm}$ less precipitation); the annual precipitation, at this time, could have been approximately $430-450 \mathrm{~mm}$.

The influence of the short-term climate change on the properties and areas of foreststeppe chernozems have been examined based on the example of three key plots. Two of these plots are located in the territory of the Belgorod Region, and one is within the territory of the Kursk Region (Fig. 3).

The periods of observations corresponded to different phases of short-term helioclimatic cycle-warm-dry and cool-wet. The presence of the indicated climatic phases is confirmed by a comparison of the climatic maps for the Belgorod Region created at different time- points (Fig. 4). The comparison of the maps, which reflect average climatic indices during 1971-2000, with the maps that characterize climatic indices during the earlier thirtyyear period (1951-1980) showed that, for last quarter of the XX century, there were a distinct increase in the annual amount of precipitation and the evolution toward a less continental temperature regime. This was reflected by the shift to the north of the January isotherms and to the south of the July isotherms (Fig. 4).

According to the observed data obtained for the Kursk Region, L.A. Bashkakova et al. [1984] established that there was a reduction in the humus content both in arable and in virgin chernozems of the Streletskaya Steppe Preserve (Table 2; key plot No. 1 on Fig. 3). As has been discovered, during the period from 

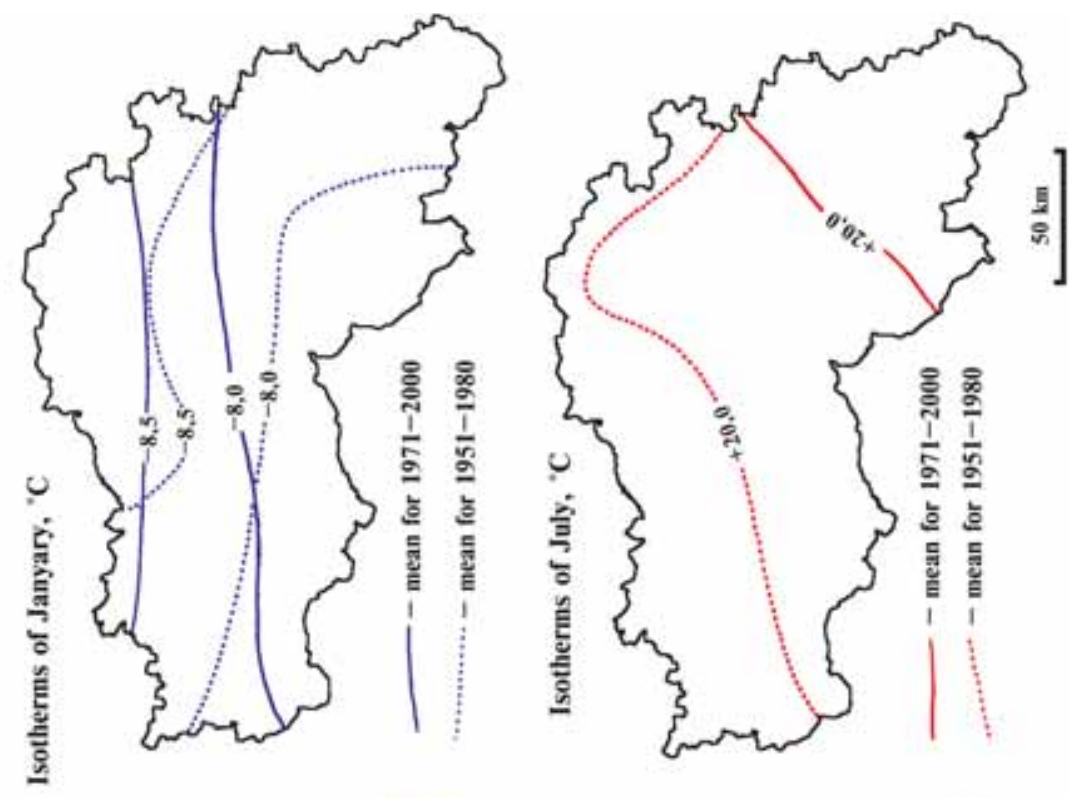

윰

충 ํํำ

ธัต

०ू जิ

돌

ํํำ

ํํํ

ํํํ ํํㅇ

으음

돈 은

훙
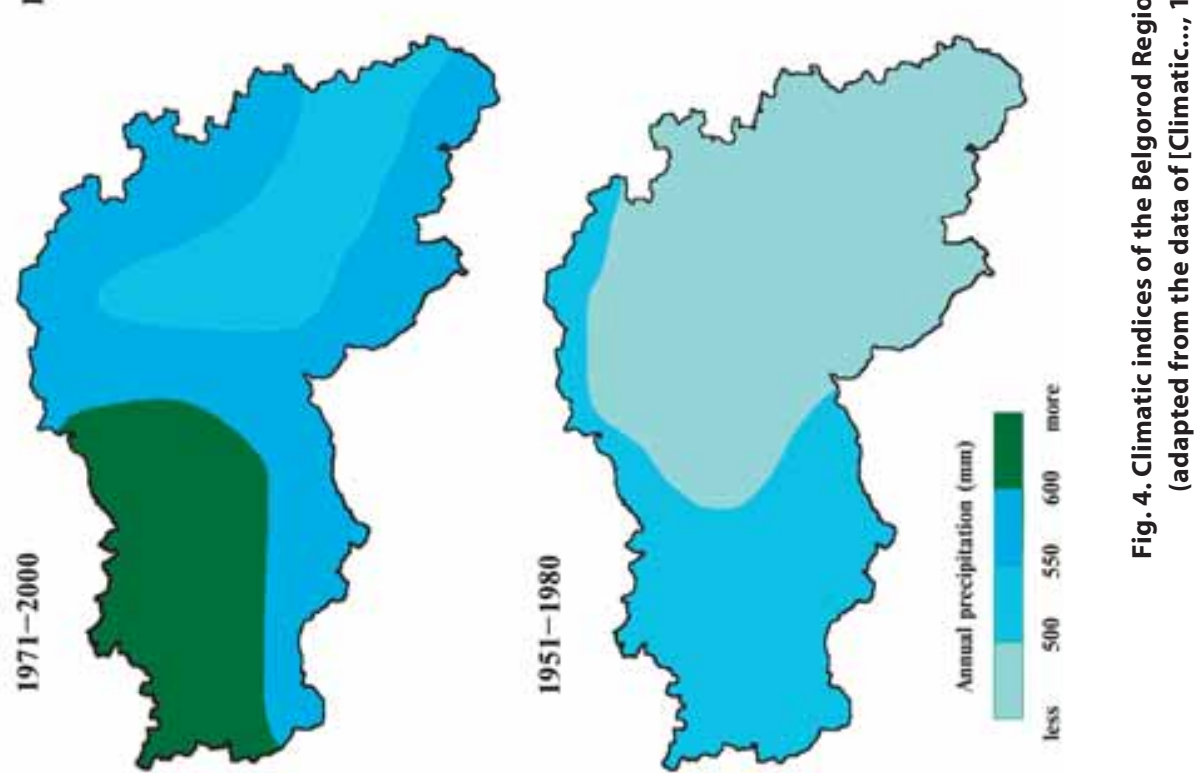
Table 2. Humus content (\% at mass of soil) in arable and virgin typical chernozems of northern forest-steppe observed in different periods (based on data [Bashkakova et al., 1984])

\begin{tabular}{|c|c|c|c|c|c|c|}
\hline \multirow{2}{*}{ Depth. cm } & \multicolumn{2}{|c|}{ Arable land since 1927} & \multicolumn{2}{|c|}{ Virgin steppe } & \multicolumn{2}{|c|}{ Mown steppe } \\
\hline & 1963 & 1981 & 1958 & 1981 & 1958 & 1981 \\
\hline $0-5$ & 8.8 & 7.1 & 11.17 & 9.1 & 11.12 & 8.7 \\
\hline $5-10$ & 8.5 & 7.1 & 8.76 & 7.3 & 7.88 & 7.2 \\
\hline $10-20$ & 8.5 & 6.7 & 7.72 & 6.4 & 6.76 & 6.5 \\
\hline $20-30$ & 7.5 & 5.7 & 6.57 & 5.4 & 5.58 & 6.5 \\
\hline $30-40$ & 6.8 & 4.9 & 6.03 & 4.8 & 5.02 & 6.0 \\
\hline $40-50$ & 6.0 & 4.1 & 4.95 & 4.3 & 4.62 & 4.6 \\
\hline $50-60$ & 5.7 & 3.8 & 4.29 & 3.3 & 4.03 & 4.2 \\
\hline $60-70$ & 5.2 & 3.2 & 3.72 & 2.8 & 3.69 & 4.0 \\
\hline $70-80$ & 4.4 & 3.1 & 2.98 & 2.6 & 3.23 & 3.3 \\
\hline $80-90$ & 3.7 & 2.5 & 2.60 & 2.2 & 3.08 & 2.5 \\
\hline $90-100$ & 3.6 & 2.1 & 2.28 & 2.0 & 2.84 & 2.3 \\
\hline
\end{tabular}

1958 to 1981, dehumification under virgin steppe was occurring in the soil profile to a depth of $100 \mathrm{~cm}$. For the study period, the intensity of dehumification in the arable land in 1927 was even less than under virgin steppe without grass mowing (Table 2). Researchers now explain that the reduction of the contents of humus and of exchangeable bases in automorphic meadow-steppe chernozems is associated with changes in conditions of soil formation and nature of vegetation. These changes occurred as a result of the recent cycle of moistening climate influence, which begun at the end of the 1960s and the beginning of the 1970s. In this case, the dynamic equilibrium moved toward leaching of exchangeable bases and the increase in humus mineralization above humification of organic matter [Bashkakova et al., 1984].

The influence of short-term climate changes on soils and the soil cover can be studied by analysis of large-scale soil maps, as discussed above, compiled through identical procedures but for different periods. Suitable for this purpose are 1:10000 scale soil maps of agricultural enterprises created by largescale soil surveys at different times-points. For example, we have carried out the temporalspatial analysis of the soil cover conditions in 1970 and 2001 within the territory of the state farm in the "Stepnoe" in the Gubkin District of the Belgorod Region (key plot "Yur'evka", Fig. 3). Also, in 1976 and 1996, the same analysis was done within the territory of the state farm "Dmitrotaranovskiy" in the Belgorod District of the Belgorod Region (key plot "Octyabr'skii", Fig. 3).

As has been shown in the comparative analysis, the areas occupied by typical and leached chernozems on the maps of 1970-1976 and 1996-2001 differ significantly (Fig. 5). In the contemporary period, the area of leached chernozems generally increased while the area of typical chernozems decreased. Furthermore, the obvious tendency was a reduction of the areas with solonetzic chernozems (plot "Yur'evka", Fig. 5).

It is possible to assume that the discovered changes have been, in many respects, caused by climatic dynamics. For example, it 

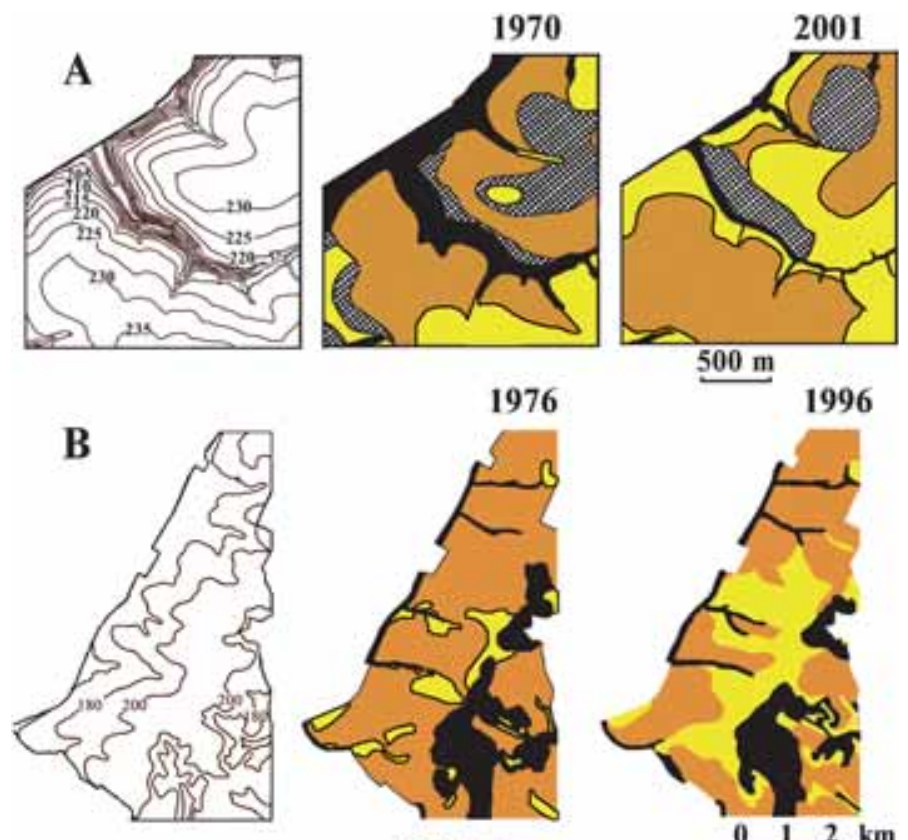

SOILS:
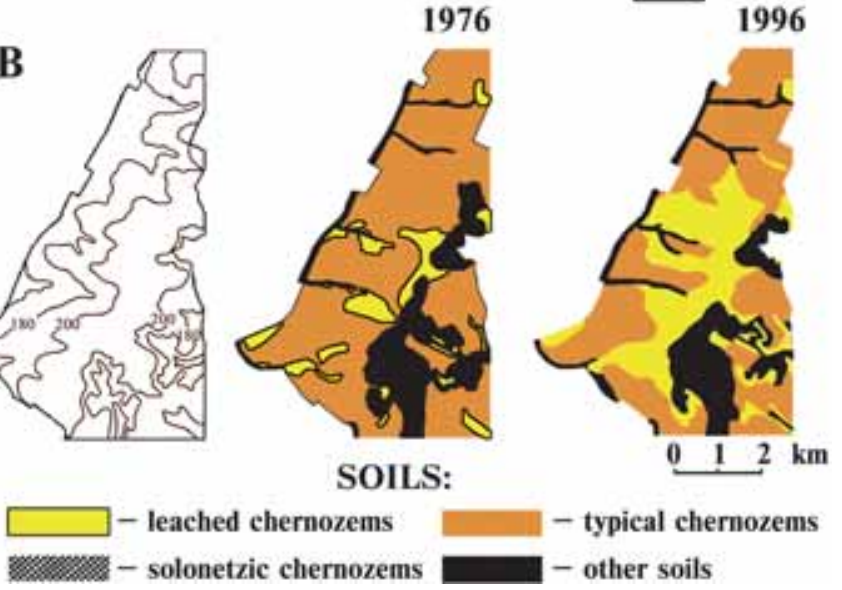

Fig. 5. Orographic maps (left figures, absolute heights are indicated in $\mathrm{m}$ ) and the soil cover of key plots "Yur'evka" (A) and "Octyabr'skii" (B) for different soil surveys periods (based on the data from [Soils..., 1976; Soils..., 1996; Soils..., 1970; Soils..., 2001])

is known that in the territory of the Belgorod Region during 1971-2000, the total annual precipitation grew substantially (Fig. 4). According to L. V. Klimenko [1992], during the last quarter of the XX century, there has been increased moistening of the climate in winter. During this period, the frequency of thaws increased. According to the observed meteorological data in the Belgorod Region from the 1990s to the beginning of the 2000s, the steady snow cover frequently appeared only at the end of the winter periods and persisted only for 2-4 weeks. We considered that during the periods of winter thaws, precipitation in the form of wet snow or rain with the absence of soil freezing could initiate leaching of soils. In our opinion, this process was one of the main reasons for the rapid (years to decades) evolutionary dynamic transformation of typical chernozems into leached chernozems, and, probably, of solonetzic chernozems into chernozems typical or leached (Fig. 5).

\section{CONCLUSIONS}

In the course of this research, it has been established that chernozems are sensitive indicators of both long-term and short-term climatic changes.

For the territory of the Central East-European Plain, the existence of two large climatic epochs with the opposing tendencies in the climatic processes have been revealed with respect to changes in the humus horizons thicknesses in automorphic steppe chernozems in the second-half of the Holocene: the earlier part of the period was arid and the contemporary is moist. Transition from the arid to the moist epochs took place near $4000 \mathrm{yr}$ BP. The duration of the Late Holocene within the study territory was 4000 years. The 4000-yr-BP boundary between steppe and forest-steppe was approximately $100-120 \mathrm{~km}$ to the northwest of its contemporary position. Near the boundary of "steppe - forest-steppe», the 
annual amounts of precipitation were, on average, $80 \mathrm{~mm}$ lower than contemporary values ( $16 \%$ of the modern annual sum).

The change from the warm-dry to the coolwet phases inside the age-long helioclimatic cycles was reflected noticeably in the properties and areas of chernozem soils. In the last quarter of the XX century, climate moistening contributed to strengthening of the dehumification in the profiles of automorphic chernozems and to the reduction of humus content in the upper meter of soils. The leaching of carbonates and of readily soluble salts contributed to the decrease in the areas occupied by typical and solonetzic chernozems and to the increase in the areas occupied by leached chernozems. The discovery that these changes are cyclically repetitive events should be considered in the development of plans for the economic management of lands for the next few years and decades
It is feasible to conduct joint international scientific research within the territories of the continents of the Northern Hemisphere for the understanding of similarities and differences in the nature of prolonged and short-term climate changes and of how they influence the properties of soils and of the soil cover. According to available data, in the territories of the northeastern part of the USA Central Plains and the center of the East European Plain, climate change is currently subordinate to regular climate variations. In the Middle Holocene, the climate of these territories was more arid than the contemporary [Aleksandrovskii and Chendev, 2009; Denniston et al. 2000; Ruhe, 1974; Woodhouse and Overpeck, 2008; and references within]. At the end of the $X X$ century within the two indicated regions, the atmospheric moisture increased [Chendev and Petin, 2009; Sauer, et al., 2009] as a reflection of climatic intra-secular cyclic recurrence.

\section{REFERENCES}

1. Aleksandrovskii, A.L. (1983) Evolution of Soils on the East European Plain during the Holocene. Moscow, Nauka, 150 pp. [in Russian].

2. Aleksandrovskii, A.L. and E.I. Aleksandrovskaya (2005) Evolution of Soil and the Geographical Environment. Moscow, Nauka, 223 pp. [in Russian].

3. Aleksandrovskii, A.L. and Yu.G. Chendev (2009) Climatic Evolution of Soils within the Great Plains of the Northern Hemisphere during the Holocene. In "Climate Change, Soils, and Environment: Proceedings of the International Scientific Seminar, Belgorod, 16-19 September 2009" Belgorod, pp. 162-169. [in Russian].

4. Bashkakova, L.A., F.F. Topol'skii, et al. (1984) Research of Physical Chemical Properties of Soils Under Cultivation and Virgin Vegetation based on the Example of the Central Chernozem preserve" In "The Geographical Study of the KMA Regions" Kursk, pp. 66-76. [in Russian].

5. Buol, S.W., F.D. Hole, R.J. McCracken, and R.J. Southard (1997) Soil Genesis and Classification, 4th Edition. lowa State Univ. Press, Ames, IA, 483 pp.

6. Bunyard, P. (2001) The Truth about Climate Change. Ecologist Report, Vol. 31, No. 9, 4-11.

7. Chendev, Yu.G. (2008) Evolution of Forest-Steppe Soils Within the Central Russian Upland during the Holocene. Moscow, GEOS, 212 pp. [in Russian]. 
8. Chendev, Yu.G. and A.N. Petin (2009) Climate Change in the XX Century and Its Influence on the Soil Cover. In "Climate Change, Soils, and Environment: Proceedings of the International Scientific Seminar, Belgorod, 16-19 September 2009" Belgorod, pp. 147-155. [in Russian].

9. Climate Change: Critical Concepts in the Environment (2002) Vol. 2. Natural Forcing Factors for Climate Change on Timescales 10-1 to 105 Years, ed. by Chambers F., Ogle M. Routledge, London, 407 p.

10. Climate Change, Soils, and Environment (2009) Proceedings of the International Scientific Seminar, Belgorod, 16-19 September 2009, ed. by Yu. Chendev. Belgorod, 177 pp. [in Russian].

11. Climate Variability and Extremes during the Past 100 Years. (2008) Vol. 33. Advances in Global Change Research, ed. by Brünniman S. et al. Springer, Berlin, 361 p.

12. Climatic Map. In the Atlas of Belgorod Region (1982) ed. by N.V. Klukin. Moscow, pp. 10. [in Russian].

13. Denniston, R.F., L.A. Gonzalez, Y. Asmerom, M.K. Reagan, and H. Recelli-Snyder (2000) Speleothem Carbon Isotopic Records of Holocene Environments in the Ozark Highlands, USA. Quaternary International, Vol. 67, No. 1, 21-27.

14. Felix-Henningsen, P. (2000) Paleosoils of Pleistocene Dunes as Indicators of Paleomonsoon Events in the Sahara of East Niger. Catena, 41, No. 1-3, 43-60.

15. Gennadiev, A.N. (1990) Soils and Time: Models of Development. Moscow, 229 p. [in Russian].

16. Global Variations of the Environment (2000) Moscow, Nauchnyii Mir, 304 pp. [in Russian].

17. Grigoryev, G.N., O.V. Kryimskaya (2005) Climatic Conditions. In"The Atlas'Natural Resources and Ecological State of the Belgorod Region". Belgorod. [in Russian].

18. Ivanov, I.V. (1992) Evolution of Soils of the Steppe Zone during the Holocene. Moscow, Nauka, 143 pp. [in Russian].

19. Jenny, H. (1941) Factors of Soil Formation. McGraw-Hill, New York, NY, 281 pp.

20. Klimenko, L.V. (1992) Variations of Temperatures within Southern Part of the USSR European Territory during the 1891-1990. Vestnik Mosk. Un-ta. Ser. 5. Geografiya, No. 1, 25-30 [in Russian].

21. Lupo, A.R. (2008) Anthropogenic Global Warming: a Skeptical Point of View. Journal of Missouri Medicine, 105:2, 22-26.

22. Ovechkin S.V. and V.A. Isaev (1985) Periodic Additional Underground Moistening as a Factor of Soil Cover Evolution. In "The Questions of Hydrology in Soil Fertility», Moscow, pp. 56-65. [in Russian].

23. Ruhe, R.V. (1974) Holocene Environment and Soil Geomorphology in Midwestern United States. Quaternary Research, 4, No. 4, 487-495. 
24. Sauer, T.J., C.L. Burras, and Yu.G. Chendev (2009) Dynamics of Forests within Eastern lowa (USA) from 1972 until 2008. In "Climate Change, Soils, and Environment: Proceedings of International Scientific Seminar, Belgorod, 16-19 September 2009". Belgorod, pp. 162-169.

25. Savin, I.Yu. (1990) Candidate's Dissertation in Geography. Moscow, 300 pp. [in Russian].

26. Sazhin, A.N. and O.V. Kozina (2000 Contemporary Climatic Tendencies and Their Reflection at the Regional Level (on Example of Lower Volga Region). In "The Scientific Discovery of the Surrounding Nature, the Dynamics of the Geographical Environment (Nature, Society, Policy): Transactions of XI congress of the Russian Geographic Society», Vol. 5. SaintPetersburg, pp. 105-106. [in Russian].

27. Soils of the State Farm "Dmitrotaranovskii», Belgorod District, Belgorod Region, and Recommendations on Their Management (1976) Belgorod, 80 pp. [in Russian].

28. Soils of the State Farm "Dmitrotaranovskii», Belgorod District, Belgorod Region, and Recommendations on Their Management (1996) Belgorod, 76 pp. [in Russian].

29. Soils of the State Farm "Stepnoe", Gubkin District, Belgorod Region, and Recommendations on Their Management (1970) Voronezh, 81 pp. [in Russian].

30. Soils of the State Farm "Stepnoe", Gubkin District, Belgorod Region, and Recommendations on Their Management (2001) Belgorod, 78 pp. [in Russian].

31. Sokolov, I.A. and V.O. Targul'yan (1976) Interaction of Soil and Environment: Soil-Memory and Soil-Moment. In "The Study and Management of the Natural Environment" Moscow, Akad. Nauk SSSR, pp. 150-164. [in Russian].

32. Sokolov, I.A., N.A. Karavaeva, A.L. Aleksandrovskii, and I.V. Ivanov (1986) Evolution of Soils: Concepts and Terms (Experience of the Development). In "The Evolution and Age of Soils of the USSR". Pushchino, pp. 5-22. [in Russian].

33. Solovyov, I.N. (1989) On the Question of Modern Evolution of the Soil Cover within the Chernozem Zone of the USSR European Part. In "The Anthropogenic and Natural Evolution of Soils and Soil Cover: Theses of Reports, All-Union Conference 10-12 January 1989, Pushchino" Moscow - Pushchino, pp. 257-259. [in Russian].

34. Spiridonova, E.A. (1991) Evolution of the Plant Cover in the Don River Basin in the Late Pleistocene-Holocene. Moscow: Nauka, 221 pp. [in Russian].

35. Woodhouse, C.A. and J.T. Overpeck (1998) 2000 years of drought variability in the Central United States. Bull. Amer. Met. Soc., 79, pp. 2693-2714. 


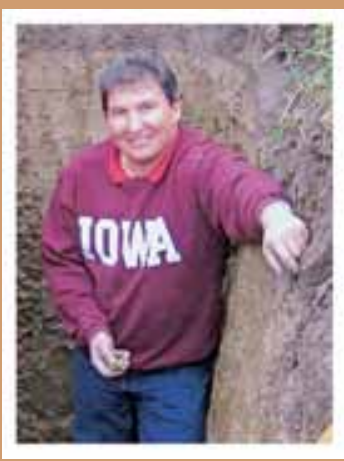

Yury G. Chendev - doctor of geographical sciences (Dr. Sci.), Head of Department of Natural Resources Management and Land Cadastre, National Research Belgorod State University. Graduated from Moscow State University (Faculty of Geography) in 1985. Soros Associate Professor (International Soros Science Education Program, DDF Foundation, 2001). Fulbright scholar of 2008, project «Agrotechnogenic Evolution of Gray Forest Soils in Landscapes-Analogues within the Forest-Steppe Zone: Northeast Central Plains, USA and Central Russian Upland, Russia», executed at the Department of Agronomy, lowa State University, the USA. Fields of his scientific activity are genesis, evolution and geography of soils, historical geography and archaeological pedology. He executed scientific investigations in many regions of Russia and other countries. He is a participant of many complex soil-archaeological expeditions. More than 100 scientific publications and text books.

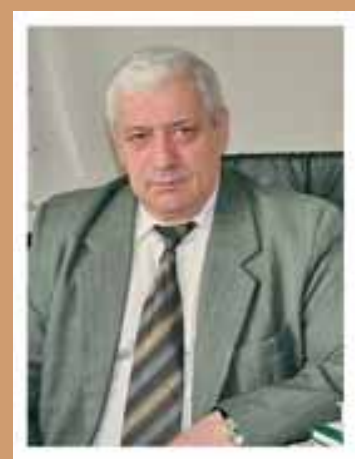

Aleksandr N. Petin - doctor of geographical sciences (Dr. Sci.), professor, Dean of Geologic-Geographical faculty of National Research Belgorod State University. Corresponding Member of Russian Academy of Natural Sciences. He is also Member of Unified Council on fundamental geographic problems at International Association of Academies of Sciences. A. Petin is Member of Coordinated Council of Belorussia-Russia-Ukraine Consortium of Universities. Laureate of the All-Russian Competition of Scientific Works «Rational management of Natural Resources and Protection of Environment - Strategy of Sustainable Development of Russia in the XXI Century» (2007). He has been rewarded by many diplomas and deeds, in their turn diplomas of Belgorod State University «Best Scientist» and National Ecological Premium «Eco-Mir». Fields of his scientific interests are physical geography, environmental geography, geomorphology, and hydrology. More than 370 scientific works, including 20 monographs and textbooks.

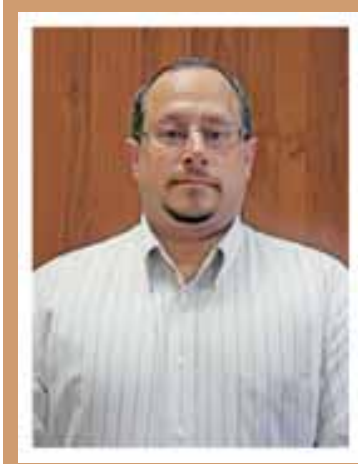

Anthony R. Lupo is a professor of atmospheric sciences and chairman of the Soil, Environmental, and Atmospheric Sciences Department at the University of Missouri. His research has been in the areas of large-scale atmospheric dynamics, climate dynamics, and climate change. He was a Fulbright Scholar during the summer of 2004, studying climate change at the A.M. Obukhov Institute for Atmospheric Physics of the Russian Academy of Sciences in Moscow. Additionally, he has served as an expert reviewer and/or contributing author to the Intergovernmental Panel on Climate Change (IPCC) Assessment Reports, and the NIPCC (Non-governmental International Panel on Climate Change) report. Dr. Lupo has published either as an author or co-author over 60 peer-reviewed journal articles in his areas of research, more than 50 articles for non-peer reviewed publications, and nearly 200 conference papers. He was recently the editor of a book on tropical meteorology. 